\begin{tabular}{|l|l|}
\hline Postprint Version & 1.0 \\
\hline Journal website & http://jhsrp.rsmjournals.com/content/16/suppl_2/16.long \\
\hline Pubmed link & http://www.ncbi.nlm.nih.gov/pubmed/21737526 \\
\hline DOI & $10.1258 /$ jhsrp.2011.011040 \\
\hline
\end{tabular}

This is a NIVEL certified Post Print, more info at http://www.nivel.eu

\title{
European priorities for research on health care organizations and service delivery
}

\author{
Johan HANSEN, WiLlemiJn SCHÄFER, NiCK BLACK ${ }^{1}$, PETER GROENEWEGEN ${ }^{2}$
}

${ }^{1}$ London School of Hygiene \& Tropical Medicine; ${ }^{2}$ NIVEL, Netherlands Institute for Health Services Research and Professor of Social and Geographical Aspects of Health and Health Care, Utrecht University, Netherlands

Objectives: To provide an overview of the principal areas of research on health care organization and service delivery and to identify priority areas from a European comparative perspective. Given the large quantity of articles produced on health care organizations, we focus on primary care and hospital care.

Method: A combination of methods was used for describing past and current research: (i) bibliometric analyses of published research in Pubmed and Embase 2000-09; (ii) a further classification of research based on a sample of 1,010 articles; and (iii) an identification of relevant EU-funded projects over the period 2000-10. An online survey of experts was carried out to identify priorities. The results were refined through conference discussions.

Results: Research into health care organizations varies considerably across Europe. This is only partly associated with differences in countries' gross domestic product or population. Studies were categorized into four main domains: intra-organizational control; interorganizational relations; patient relations; and governance and accountability. Past and current research may not reflect future priorities as the domain of 'inter-organizational relations' is regarded by most experts as the top priority for the future, while the smallest share in the sample of published research and EU-funded projects fell into that category. Expert views show considerable homogeneity, regardless of their role in the health care system or their country.

Specific future priorities include the integration of care across organizational boundaries (including the relationship between primary and secondary care), patient involvement and participation and workforce skill-mix.

Conclusions: The research priorities identified in this study relate to important shared challenges in Europe's health care systems. This makes cross-border learning important, especially given the clear geographical variation in health services research (HSR) funding and capacity in Europe.

\section{INTRODUCTION}

Health care organizations are a crucial component of health care, being the settings where supply and demand interact: users, or patients, seek care for a health problem and health care professionals provide health services in response.1 They vary from large structures, like general or specialized hospitals to small primary care practices or health centres.2-4 In order to develop evidence-informed policies that can 
improve health care in Europe, evidence is needed about the structures, care processes and outcomes of health care organizations.5 Our objective is to contribute to this by providing an overview of the principal areas of research on health care organizations and their service delivery, and to identify future research priorities at the European and country level. In order to achieve this, two steps are required as research on health care organizations is wide-ranging. The first is to classify types of research. Following Lammers6 and Delnoij and Groenewegen,1 we distinguish four domains of research on health care organizations. One is intra-organizational control, focusing primarily on how organizations arrange their work internally, such as by differentiation or specialization.7 Topics include workforce and skill-mix,8 creation of multidisciplinary teams 9 and reconfiguring services. 10 The second domain is inter-organizational relations, for organizations are part of networks. Topics include the continuity of care between organizations, 11 the transfer from secondary to primary care12 and the spatial distribution of services, including cross-border health care.13-14 The third domain, patient relations, deals with patient involvement and participation,15 patient compliance,16 patient delay 17 and demand management.18 Finally, the fourth recognizes that organizations are subject to governance and accountability, for instance on patient safety and the level of market exposure. Topics here include the assessment and improvement of quality and safety,19 the relationships between professionals and managers, 20 and the regulation of professions or provider organizations.21 As a second step, we limited the scope to primary care and hospital care. While this reduces the breadth of the literature searches, it provides sufficient information for country comparisons of specific topics. Both sectors are generally considered key elements of all European health care systems. Primary care organizations provide care that is seen as essential, universally accessible and should be provided at an affordable cost.22-23 As it is often seen as the linchpin of effective health care delivery, many European Union (EU) Member States, new and old, emphasize the need to develop their primary care systems.24 Hospitals are the largest component of European health care systems in terms of spending; the hospital sector typically absorbs 35-70\% of a country's health care budget.25 This highlights the need for more evidence on better ways to configure hospital services and how to change the way they operate.

Our aim was to identify, for both sectors, the principal areas of past and current research on health care organization and service delivery, and to relate this to future priorities at the European and country level. We focused on two questions:

What types of research on the organization of primary and hospital care have been conducted in the past decade, or are currently being conducted, and do these differ between European regions?

How does this research match future priorities as seen by experts in Europe: which domains have been studied extensively and which are under-researched?

\section{METHODS}

We answered the first question by doing bibliometric analyses, a further classification of a sample of articles and an inventory of EU-funded studies. The second question was answered by a survey among experts and discussions at several conferences.

\section{Bibliometric analyses}

We obtained an overview of European literature published between January 2000 and December 2009 through a search of Pubmed and Embase.

Thirty-three countries were selected, including EU Member States, candidate Member States and members of the European Economic Area (EEA).

A manual scan to determine relevant keywords was carried out on all abstracts between July 2007 and July 2009 ( $n=506)$ of BMC Health Services Research. Articles that could be considered as describing research on health care organizations led to the identification of relevant keywords from the thesaurus of Medical Subject Headings (MeSH). These were then tested on a volume of another journal (Health Affairs, 2008). Next, keywords were added or removed until the search led to a list of articles, which included $90 \%$ of the articles which had been manually selected. The final list of keywords was also translated into a list of relevant keywords for Embase.

Inclusion criteria were that the article needed to address human health and contain an abstract, published in English. An overview of the search keywords and criteria is provided elsewhere.26 This yielded 19,624 articles from Pubmed and 8,806 articles from Embase. Titles, authors, keywords, publication dates and 
abstracts were downloaded for further analysis. Duplicates $(1,426)$, as well as references on non-European research (such as on 'New England') were excluded, which led to 23,617 articles. Keywords were analysed, together with all relevant sub-keywords.

Some keywords were clustered together based on the topic. For example 'patient education, participation, satisfaction' (PEPS) is a combination of six keywords from the results of both databases that together form one keyword. In total, 27 keywords were analysed.

\section{Classification of a sample of studies}

As keyword searches only provide limited information about an article's contents, a sample of 1,010 articles was drawn for further analysis. The sample was stratified by country, 30 articles being randomly selected from each of the 33 countries. For countries with less than 30 articles in the databases, all articles were selected. If an article dealt with health care organizations, it was then classified as follows:

- Domain: each article was assigned to one or more of the following domains: intra-organizational control; inter-organizational control; patient relations or governance and accountability;

- Topic: based on a first scan of the literature a number of topics were identified. Each article was assigned to one or more topics. If the category 'other' contained a frequently occurring theme, it was reclassified into an extra topic. In total 35 topics were distinguished (see Box 1);

- Sector: primary care, hospital care or both.

Of the 1,010 articles selected, 459 (45\%) articles could be considered as dealing with research on health care organizations. This low specificity is quite similar to results found elsewhere.1,27

\section{Inventory of EU-funded projects}

A review of research projects funded by the EU offers an indication of international comparative research that is currently being conducted or recently finished. We reviewed EU-funded projects looking at two databases of the European Commission, namely the project database of the Executive Agency for Health and Consumers (EAHC), which implements the EU Public Health Programme led by the Directorate General for Health and Consumers, and the project database, Cordis, the information service on current and past EU research Framework Programmes. Projects were first selected based on two keywords: 'primary care' and/or 'hospital'.

In addition, a manual scan took place of all projects funded under pillar 3, 'Optimizing the delivery of health care to European citizens', of the current EU Seventh Framework Programme. A first scan limited to currently running EU projects only led to the identification of 29 relevant projects. Therefore, we extended the search to all projects in the period 2000-10.We first identified 36 projects in EAHC and 637 projects in Cordis. Next, all project titles were manually scanned to eliminate clinical or biomedical research.

Ninetythree projects were investigated further by evaluating their project descriptions. In total, two-thirds, 62 projects, addressed HSR at an organizational level. These projects were then classified in the same way as the previous sample of articles.

\section{Expert survey}

An online survey on behalf of the Health Services Research into European Policy and Practice (HSREPP) project was carried out among researchers and decision-makers in order to assess views on upcoming HSR priorities. A description of the survey and its responses is provided elsewhere.26 The survey contained a section on health care organizations which was completed by 82 of the 295 respondents (28\%). Of these 82 respondents, $71 \%$ could be considered researchers and $26 \%$ decision-makers in national government or health service management. In addition, $4 \%$ had another role. A geographical distinction is made between respondents from the EU's initial 15 Member States (70\%), its new Member States (21\%), or from other European countries (10\%), mostly from the EEA.

\section{[вох 1]}

\section{Verification of the survey responses}

More detailed discussion took place with experts at a working conference on HSR in Europe in The Hague in April 2010, organized as part of the HSREPP project. About 90 participants, working in three groups of 
30, discussed research priorities. Follow-up discussions were held at the annual conference of the European Health Management Association (EHMA) in June 2010 and the biannual conference of the European Forum for Primary Care (EFPC) in August 2010, in order to verify the topics identified and to suggest additional topics. The former involved experts in health management and policy at an organizational or national level, and the latter provided an opportunity to test findings among experts in primary care. In addition to workshop discussions, the EHMA meeting also incorporated a replication of the online survey, providing additional findings especially among decisionmakers, 40\% of all EHMA respondents belonging to that category. These inputs were then used to set an agenda for health services research (HSR) on organizations and service delivery.

\section{RESULTS}

\section{What research has been undertaken in the past decade?}

\section{Research output in Europe}

A bibliometric analysis revealed more than 23,000 publications from the last decade with keywords indicating topics that address health care at an organizational level. Figure 1 shows the increase in the number of publications per year on each country. Results are summarized for Europe as a whole and for five clusters of countries: the UK and Ireland; the other EU-15 countries; new EU Member States; EU candidate Member States; and other countries. As the amount of research on the UK and Ireland is far higher than in the other countries, the number of publications for these countries is divided by 10 in order to fit it on the graph. On average, the number of HSR publications shows a steady increase between 2000 and 2007 for all groups of countries, with an average growth rate of $10 \%$ per year. After 2007 this reversed, with an average decline of $11 \%$ a year. In part, this appears to be due to a delay in assigning MeSH terms to articles: when the count of articles was done at an earlier stage, in April 2010 instead of November 2010, the number of publications for 2009 was much lower, while those for 2007 and 2008 remained almost unaltered. While this accounts for part of the drop, there still appears to be a reduction in research production, similar to that found in the study on health care systems in this issue.27 The UK and Ireland have by far the highest HSR production.

Research on new and candidate Member States is far lower than in the European region as a whole. In part, this is caused by language bias in Pubmed and Embase, since not all non-English journals incorporate an English abstract and are included in one of the databases.

Differences in the numbers of publications between countries reflect, in part, their population size and their wealth. There is a positive but weak correlation between the number of publications on a country and its population $(r=0.35)$ and its Gross Domestic Product (GDP) $(r=0.44)$. Correlations of both variables with numbers of publications being produced in a country are almost identical.

\section{[FIGURE 1]}

Another element is the relationship between what is being published on a specific country, using the country as a keyword, versus what is published from a country (country in the address field). Overall, more research is produced on a country than from a country, reflecting in part that studies address multiple countries. It also indicates the co-authorship of many publications, in part by researchers who move from one country to the other, for example, researchers from 'low research output' countries working in 'high research output' countries. Figure 2 shows the geographical distribution for research on all 33 countries, corrected for per billion GDP. Shown in this manner, it is apparent that it is not so much 'old versus new Europe' that makes the difference. Instead, countries such as Estonia and Croatia are relatively more often the subject of study than some large EU Member States such as France and Germany, adjusting for their GDP per capita. A similar pattern emerges with the number of publications produced in a country.

This illustrates that language is a strong factor, as the search was limited to papers with an abstract in English. While in absolute numbers, France and Germany have high HSR production, the available knowledge on these countries in English is relatively low for their size and GDP per capita. 
The national versus international focus of HSR is another element that can be identified from the data. Ninety percent of studies appear to be based on one country, with only one country name in the list of keywords.

About 8\% include two countries, while the remainder makes a comparison between three or more countries. Studies on six or more countries are very rare.

\section{Main research topics}

Analysis of the ten most common keywords gives a general view of the types of research topics investigated (Figure 3). Almost half of all articles (46\%) were on 'professional practice', which refers to professional activities and the performance of duties for the provision of health care. Keywords included 'group practice', 'nursing,' or 'referral and consultation'. The second most common topic was 'physicians' (30\%), indicating the historically strong emphasis on the supply of care rather than the demand for care. Regions differ somewhat in the topics studied. For example, in studies on EU-15 countries, a larger share was related to 'physicians', 'health facilities' and 'guideline adherence' than in candidate Member States. In contrast, articles that addressed these latter countries more often contained keywords on 'professional practice', 'patient care management' and 'patient safety'. Additional results show large differences in the occurrence of specific keywords between individual countries. For example, research in Macedonia and Malta was completely accounted for by four of the ten selected keywords, while in countries like Ireland, Greece and the UK all ten selected keywords could be identified.26

\section{[FIGURE 2,3,4]}

\section{Further classification of references}

To provide a better picture of the topics addressed, we reviewed a sample of 1,010 HSR article abstracts, $45 \%$ of which dealt with research on health care organizations. Of these selected articles, the largest proportion (41\%) addressed the area of governance and accountability, which includes topics such as the effectiveness of treatment and the regulation of professions (Figure 4). About a third of articles (31\%) were related either to intra-organizational relations (for example, the internal workforce or changing service provision) or to patient relations (28\%). Only $11 \%$ were on inter-organizational relations, possibly because this topic deals with phenomena that are relatively new on the policy agenda, such as the continuity of care across organizations.

Differences between European regions are fairly small. A comparison with EU-funded projects shows that the latter closely resemble the topics addressed in published research (Figure 4). For example, the largest proportion of projects deals with 'governance and accountability', while 'inter-organizational relations' are covered least often. The largest difference is in 'patient relations', being more common among published research (28\%) than in EU-funded projects (13\%). The same analysis also enables us to determine the health sector addressed. When it comes to published research, a similar share of articles relate to primary care (32\%) as to hospital care (28\%). Another 19\% deals with both, although in most cases it does not involve studies on the relationship between both sectors, but health care in general, such as physician behaviour. At a European comparative level, research addressing primary care is uncommon (8\%), whereas about half of all EU-funded projects cover both sectors.

\section{What research should be done in the future and how does this relate to past and current research?}

\section{Expert survey priorities}

An online survey among experts in Europe focused on priorities for future research. Of the four research domains, the one most frequently prioritized was interorganizational relations $(71 \%)$ followed by patient relations (50\%). The other two areas each attracted 43\% support (Figure 4). Decision-makers tended to be more selective than researchers, prioritizing fewer areas.

Other than that, there is considerable homogeneity in expert views, regardless of their role in the health care system or their geographical background. When comparing these research priorities with published 
research and EU-funded projects, it is clear that the dimension of inter-organizational relations has received much less attention than respondents suggest it should in the future.

A ranking of most mentioned topics is provided to make clear which ones need more research (Figure 5).

The left hand side of the figure shows how often a topic has been studied. It is clear that the two most often mentioned topics address integration within, and between, primary and secondary care, which should ideally be studied together. In addition, many of the most frequently mentioned topics have hardly been addressed with the exception of safety and quality, which is a key element in many studies.

Similarly, some other topics, such as 'workforce', 'e-health' or 'patient involvement' appear to be receiving increasing attention and are seen as important for the future. Additional topics such as 'chronic disease management', 'continuity of care' and 'creation of multidisciplinary teams' are also considered priorities while they are hardly being addressed at present. At the level of European-funded projects chronic disease management is already catching up.

\section{Working conference discussions}

The three most mentioned topics from the preliminary expert survey and bibliometric analyses were selected for discussion in more detail at the project's working conference.

In the domain of governance and accountability no topic was selected, because of its inclusion in another part of the conference on health systems research.

These discussions led to the identification and refinement of a large number of topics, summarized below.

1) Integration of care across organizational boundaries What integration of services, organizations or professions entails varies between countries, thus hampering international comparison. Conference participants also pointed to a clear lack of data and evidence as to whether integration improves patient outcomes and experience, preferably at reduced cost. We should therefore learn more about drivers and success factors for integration of care, and which forms of integration are suitable for which types of patients, and under which conditions. Can integration also be achieved in new organizational forms, such as care networks? The topic would also benefit from a comparison with the two other main fields of discussion, patient-centred care and skill-mix.

2) Patient-centred care and patient involvement in health care settings Many policy documents refer to the importance of patient-centred care, which can be studied at the level of the health system as a whole, at the organizational level, and at the level of individual patients. From an international perspective, the use and interpretation of the concept can vary due to differences in cultural backgrounds.

Policy can benefit from international comparisons, aimed at understanding how incentives for patientcentred care vary due to effects of the (regulatory) environment of the health care system, and the tensions thatmay arise between professional guidelines and patient-centred care.

From a patient perspective, more insight is beneficial about the overlaps and discrepancies between patient needs and their expectations, and the most suitable other patient groups. Further research can facilitate the use of patient-centred care in practice, by means of an evaluation of strategies, interventions and incentives that aim to empower and involve patients or that raise professionals' awareness to facilitate this. A final theme that emerged is the relationship, both positive and negative, between patient involvement and technology. Do new technologies work for all patient groups?

\section{[FIGURE 5]}

3) Evaluating the skill-mix, organization and delivery of care Although international comparisons are considered difficult, there is a clear need for more insight into variations across Europe into the tasks and specialization of professionals, and their consequences for the quality of care. Linked to this are several factors, including the role and use of guidelines, their implementation and the shift from secondary to primary care: which elements, such as training, type of organization, leadership and skill-mix are required to meet future health needs, in part, when transferring health care to primary care settings? In addition, not much is known about the effects of team climate and composition on performance, as well as on the 
limitations and possibilities that professional roles and (inter)professional education impose on skill-mix utilization.

Understanding is also often lacking as to which interventions, both technological and organizational, have improved the quality of care. The core factors of such interventions need to be understood as does the degree to which they are applicable, independent of the (national) context.

Follow-up meetings

The domain of inter-organizational relations was confirmed as a priority area in the discussions held at two follow-up meetings during conferences organized by EHMA and EFPC. In the online survey, EHMA respondents placed emphasis on governance topics more often than other respondents. In particular, the relationship between managers and clinicians, and the regulation of professionals and provider organizations was stressed.

This was shared in the EHMA workshop discussions.

Leadership and management were mentioned as especially important in times of change. At the EFPC meeting, the emphasis was on primary care, leading to the identification of similar topics to those identified earlier, such as the importance of the integration of care, and the role of primary care in diminishing health care inequalities and health care costs.

Moreover, both EHMA and EFPC conferences highlighted a number of shared views, one being the importance of determining which research needs to be addressed at a national level and which at European level. Other topics shared were the importance of human resource issues and the role of community care in relation to primary care.

\section{DISCUSSION}

\section{Main findings}

After a period of growth from 2000 to 2007 when the number of publications on health care organizations increased by $10 \%$ a year, the research area appears to have had to retrench with $11 \%$ annual declines in the following two years. The reason for this trend is not apparent given that we are not aware of a substantial drop in research funding over the period. Research activity varies dramatically across Europe, with a particularly high share of UK and Ireland-based studies.

As selected publications had to incorporate an abstract in English, this may have led to an underestimate of the output from countries that have non-English language journals. It is also apparent that only a small share of studies addresses more than two countries.

This lack of comparative studies hampers better understanding of the effects of health care interventions or policy measures in different settings. Can their effectiveness or ineffectiveness be explained by contextual factors, such as the way the health care system is organized or financed?28 The large variation in research topics between countries reflects differing concerns and interests.

Comparing published research with projects funded by the EU suggests that there has been no recent alteration in priorities or interests. However, past and current research does not reflect experts' views of future priorities.

The clearest discordance is research on interorganizational relations. Most experts viewed this as a priority, yet it represented only the smallest share of past and current research activity. There was considerable agreement between the experts regardless of their role in the health care system or their geographical background.

There is a need for more knowledge in all four research domains. Moreover, there is an urgent need for more evidence on the best way to configure hospital and primary care services, and to change the way both sectors operate. This is especially the case in light of Europe's ageing population, which requires the integration of separate parts of health care systems, and a shift in emphasis from acute, hospital care to preventive care and to care at home and in the community.29-31 Such a comparative perspective is already being taken in much research funded at the European level. This is far less the case with regard to patient involvement. In an era where health care needs to become more patientcentred, it appears that EU-funded research is not yet following this approach. It is often argued that as educational levels in the population rise and people become more knowledgeable concerning health care, they prefer more involvement and participation in important decisions affecting their health.32-33 This theme also emerged in the similar 
priority-setting studies of Academy Health in the USA in 2006 and the Canadian exercise, 'Listening for Direction,' in 2008.34-35 In the former, mostly providers and consumer advocates listed this as amajor priority area. Another topic identified, workforce and skill-mix, is strongly related to the need formore efficient allocation of human resources, given the declining workforce in health care.36 In a large variety of studies, the same topic area has been regarded a priority, including the above mentioned studies, as well as recent scoping exercises for the EU Presidency of Belgium in 2010 and for the World Health Organization.37-38

\section{Limitations of the study}

Our focus was limited to primary care and hospital care, excluding other areas of the health care sector. The bibliometric research was restricted to two databases, though we believe they include the vast majority of relevant journals. We made no attempt to include 'grey' publications. Limiting our research to publications that included an English language abstract will have meant that a substantial amount of research in some countries may have been excluded. In addition, only analysing $\mathrm{MeSH}$ terms from databases led to low specificity in identifying studies that indeed address organizational topics. For this reason, an additional classification of a smaller sample of articles was made to get a better view of the topics addressed. Finally, our attempt to obtain information on current or recently finished research was limited to EU-funded studies which represent only a small proportion of all relevant research.

When reflecting on the methods used to establish priorities for the future, it is clear that each has its pros and cons. The combination and triangulation of sources of information provides the most stable set of future priorities.

Comparable studies in the past have also used multiple approaches.34- 35,39 It shows that one cannot only depend on surveys. Discussion provides more insight into the specific directions to be taken. Two elements play a role in this. One is that results are in part dependent on presenting the right classification to respondents.

To avoid this problem of steering respondents' views, a broad selection of topics was provided together with the opportunity to provide open answers. A second element lies in the comparison between past and current research, and future priorities. The fact that some topics have already been studied extensively in the past may not indicate that future research is no longer necessary, but rather reflects the continuing importance of this topic. It also calls for future research to make use of such previous findings.

\section{Implications and recommendations}

Our review of past and current research on health care organization and service delivery suggests that research undertaken so far does not reflect the views of European experts on future priorities. Much research has either focused on the hospital sector or on primary care. In contrast, the relationship between both sectors has been under-researched despite being in constant development, with new organizational forms developing at the interface between both sectors, ranging from loose co-operation to integrated 'care chains'.40-42 This discordance illustrates the need to monitor priorities for research on a regular basis. At the same time, the strong similarity in the priorities identified in this study compared to those in other recent studies illustrates how the same challenges and priorities are shared throughout the EU and beyond. There remains a clear geographical dimension to HSR, with new and candidate Member States having a larger need for information than older Member States. In part, this is a reflection of the availability of research funding as well as research capacity. Comparative studies should involve these countries in order to make European research relevant to their specific context and to future HSR capacity. While each country can study the organization and delivery of services in their own system, there is much to be gained from comparative studies. This calls for the ability to extract lessons of international relevance from single country studies using similar methods to those used in other countries or by comparing different sectors or regions within one country. Ideally, more studies should be cross-national, as the wide variety of ways of organizing services in different countries provides Europe with an interesting natural experiment to assess and determine the impact of different models of care.

The opportunity this presents needs to be exploited if the full benefits that could accrue from research on the organization and delivery of care are to be realized. 


\section{ACKNOWLEDGEMENTS}

The research summarized in this supplement ws funded as part of the European Commission's Seventh Framework Programme (FP7/ 2007-2013) under grant agreement 223248. We wish to thank Elena Meshcheriakova (NIVEL, the Netherlands) who assisted in the literature searches and are grateful for all ideas provided by participants to a workshop session dedicated to health care organizations during the working conference 'HSR in Europe', and to the experts who facilitated and reported on these sessions: Judith Smith (The Nuffield Trust, England), Jeni Bremner (EHMA, Belgium), Ronald Batenburg (NIVEL, the Netherlands) Ellen Nolte (Rand Europe, UK), Anne-Karin Lindahl (NOKC, Norway) and Wienke Boerma (NIVEL, the Netherlands).

\section{REFERENCES}

1 Delnoij D, Groenewegen PP. Health services and systems research in Europe: overview of the literature 1995-2005.

Eur J Public Health 2007;17(Suppl. 1):10-13 2 McKee M, Healy J (eds). Hospitals in a changing Europe. Buckingham: Open University Press, 20023 Casalino LP, Devers KJ, Brewster LR: Focused factories? Physician-owned specialty facilities. Health Affairs 2003; 22:56-67 4 Grol R, Giesen P, van Uden C. After-hours care in the United Kingdom, Denmark, and the Netherlands: new models. Health Affairs 2006;25:1733-7 5 Donabedian A. Evaluating the quality of medical care. The Milbank Memorial Fund Quarterly 1966;44:166-203 6 Lammers CL. The comparative sociology of organizations.

Annual Review of Sociology 1978;4:485-510 7 Sochalski J, Aiken LH, Fagin CM. Hospital restructuring in the United States, Canada and western Europe: an outcomes research agenda. Medical Care 1997;35(Suppl):10,OS13- OS25 8 Sibbald B, Shen J, McBride A. Changing the skill-mix of the health care workforce. J Health Serv Res Policy 2004;9:28-38 9 Ouwens M,Wollersheim H, Hermens R, Hulscher M, Grol R. Integrated care programmes for chronically ill patients: a review of systematic reviews. Journal for Quality in Health Care 2005;17:141-146 10 Spurgeon P, Cooke M, Fulop N, et al. Evaluating Models of Service Delivery: Reconfiguration Principles. Research Report Produced for the National Institute for Health Research Service Delivery and Organisation programme.

SDO Project 08/1304/063, 201011 Haggerty JL, Reid RJ, Freeman GK, et al. Continuity of care: a multidisciplinary review. BMJ 2003;327:1219-1221 12 Atun R. What are the advantages and disadvantages of restructuring a health care system to be more focused on primary care services? Copenhagen: WHO Regional Office for Europe, Health Evidence Network report, 2004.

See: http://www.euro.who.int/document/e82997.pdf (last accessed 15 December 2010) 13 Joseph AE, Phillips DR. Accessibility and utilization: geographical perspectives on health care delivery. London: Harper \& Row Ltd, 198414 Dussault G, Franceschini MC. Not enough there, too many here: understanding geographical imbalances in the distribution of the health workforce. Human Resources for Health 2006;4:12 15 O'Connor AM, Rostom A, Fiset V, et al. Decision aids for patients facing health treatment or screening decisions: systematic review. BMJ 1999;319:731 16 Van Dulmen S, Sluijs E, Van Dijk L, et al. Patient adherence to medical treatment: a review of reviews. BMC Health Services Research 2007;7:55 17 Richards MA, Westcombe AM, Love SB, et al. Influence of delay on survival in patients with breast cancer: a systematic review. The Lancet 1999;353-9159:1119-26 18 Jack EP, Powers TL. A review and synthesis of demand management, capacity management and performance in health-care services. International Journal of Management Reviews 2008;11-2:149-174 19 Klazinga NS, Fischer C, ten Asbroek A. Health services research related to performance indicators and benchmarking in Europe. $J$ Health Services Research \& Policy 2011;16(Suppl 2):38-47 20 Dückers MLA, Stegeman I,

Spreeuwenberg P, et al.

Consensus on the leadership of hospital CEOs and its impact on the participation of physicians in improvement projects. Health Policy 2009;91-3:306-313 21 Trubek LG, Rees JV, Bryce Hoflund A, et al. Health care and new governance: The quest for effective regulation.

Regulation \& Governance. Special Issue 2008;2-1:1-8 22 World Health Organization. Declaration of AlmaAta.

International Conference on Primary Health Care, Alma-Ata, USSR, 197823 World Health Organization. TheWorld Health Report 2008: Primary Health Care - Now More Than Ever. Geneva:World Health Organization 200824 Kringos DS, Boerma WG, Hutchinson A, et al. The breadth of primary care: a systematic literature review of its core dimensions. BMC Health Services Research 2010;10:65 25 Rechel B, Wright S, Edwards N, et al. Introduction: hospitals within a changing context. In: Rechel B, Wright S, 
Edwards N, Dowdeswell B, McKee M (eds). Investing in hospitals of the future. Copenhagen: WHO Regional Office for Europe on behalf of the European Observatory on Health Systems and Policies, 2009 26 Hansen J, Scha" fer W, Black N, Groenewegen PP. Health care organizations and service delivery. In: HSR-Europe.

Health Services Research into European Policy and Practice.

Final report of the HSREPP project. Utrecht: NIVEL, 2011.

See: http://www.healthservicesresearch.eu 27 Velasco Garrido M, Hansen J, Busse R. Mapping research on health systems in Europe: a bibliometric assessment.

J Health Services Research \& Policy 20;16(Suppl 2):27-37 28 Gonza'lez-Block MA. Comparative research and analysis methods for shared learning from health system reforms.

Health Policy 1997;42:187-209 29 Hofmarcher MM, Oxley H, Rusticelli E. Improved health system performance through better care coordination.

OECD Health Working Paper No. 30, OECD, 200730 Frenk J. Reinventing primary health care: the need for systems integration. Lancet, 2009;374:170-173:11 31 Curry N, Ham C. Clinical and service integration. The route to improved outcomes. London: The King's Fund, $201032 \mathrm{Mead}$ N, Bower P. Patient-centeredness: a conceptual framework and review of the empirical literature. Social Science \& Medicine 2000;51:1087-1110 33 Herzlinger RE. Consumer-Driven Health Care. Implications for providers, payers, and policymakers. San Francisco: Jossey-Bass, 200434 AcademyHealth.

Strengthening the Field of Health Services Research: A Needs Assessment of Key Producers and Users.

Washington DC: AcademyHealth, 200635 Law S, Flood C, Gagnon D, on behalf of the Listening for Direction III partners. Listening for Direction III. National consultation on health services and policy issues 2007- 2010. Final Report. Ottowa: Canadian Health Services Research Foundation and Canadian Institutes of Health Research, Institute of Health Services and Policy Research, 200836 EC DG-ECFIN. The 2009 Ageing Report: economic and budgetary projections for the EU-27 Member States (20082060). Joint Report prepared by the European Commission (DG ECFIN) and the Economic Policy Committee (AWG). Luxembourg: Office for Official Publications of the European Communities, 200937 Dussault G, Buchan J, Sermeus W, Padaiga Z. Assessing future health workforce needs. Policy summary prepared for the Belgian EU Presidency Conference on Investing in Europe's health workforce of tomorrow: scope for innovation and collaboration. La Hulpe: World Health Organization, 201038 Jimba M, Cometto G, Yamamoto T, et al. Health workforce: the critical pathway to universal health coverage. Background paper for the global symposium on health systems research 16-19 November 2010. Montreux, Switzerland. See: http://www.hsr-symposium.org/images/ stories/10health_workforce.pdf (last accessed 15 December 2010) 39 Cherry C, Anderson S. Refreshing the National Listening Exercise: Report of the Findings. London: National Co-ordinating Centre for NHS Service Delivery and Organisation R\&D, 2002 40 Goldsmith J. The Illusive Logic of Integration. The Healthcare Forum Journal 1994;36:36-42 41 Saltman RB, Figueras J (eds). European health care reform.

Analysis of current strategies. WHO Regional Publications, European Series, No. 72, 199942 De Blesser L, Depeitere R, de Waele K, et al. Defining pathways. Journal of Nursing Management 2006;14:553-563

\section{FIGURES AND BOXES}


Box 1 Topics used to classify past and current research, and future priorities

Domain 1. Intra-organizational control

1. Workforce skill-mix; professional boundaries; training

2. Creation of multidisciplinary teams

3. Increasing scale of health care organizations

4. Continuity of care across professional boundaries

5. Chronic disease management

6. Integrated care

7. Changing services provided by health care organizations

8. Other

\section{Domain 2. Inter-organizational control}

9. Shifting from secondary to primary and community care

10. New and (entrepreneurial) health care organizations

11. Continuity of care across organizational boundaries

12. Cross-border health care

13. Scale differences between health care organizations

14. Reconfiguration of services

15. Regionalization

16. Inequalities and distribution

17. Other

\section{Domain 3. Patient relations}

18. Demand management (e.g. pre-authorization)

19. Balancing needs and demands (e.g. evidence-based versus patient-centred care)

20. Patient delay/waiting

21. Patients' reasons for help-seeking/lay referral

22. Patient involvement and participation (e.g. expert patient; coproduction of health)

23. Use of eHealth (e.g. telemedicine, telehealth)

24. Patient compliance and patient adherence to treatment guidelines

25. Enhancement of public information on the quality of providers for informed choice

26. Other

\section{Domain 4. Governance and accountability}

27. Assessment and improvement of quality and safety

28. Balancing efficiency and quality

29. Regulation of professions

30. Regulation of provider organizations

31. Planning/commissioning/purchasing services (e.g. funding methods; reimbursement methods)

32. Treatment guidelines

33. Treatment effectiveness or outcomes

34. Relationships between managers and clinicians

35. Other 
Hansen, J., Schäfer, W., Black, N., Groenewegen, P.P. European priorities for research on health care organizations and service delivery. Journal of Health Services Research \& Policy: 2011, 16(Suppl 2), 16-26

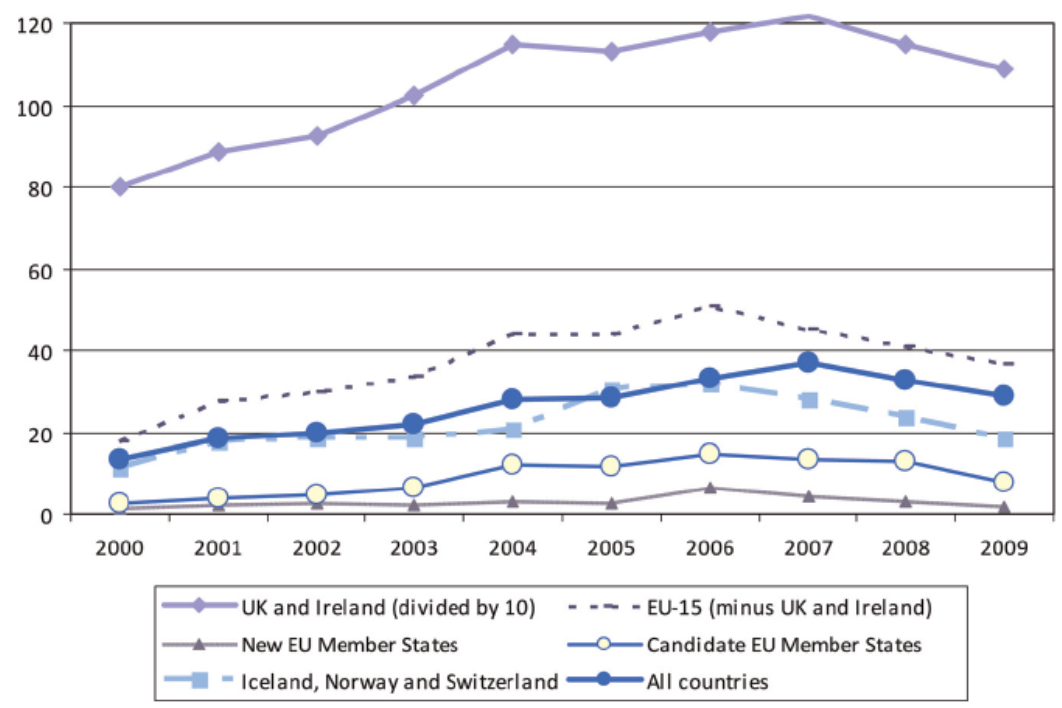

Figure 1 Average number of publications per year per country with country in keyword for all 33 European countries by clusters of countries "EU-15 = Austria, Belgium, Denmark, Finland, France, Germany, Greece, Italy, Luxembourg, the Netherlands, Portugal, Spain, Sweden (minus UK and Ireland)

** New EU Member States = Bulgaria, Cyprus, Czech Republic, Estonia, Hungary, Latvia, Lithuania, Malta, Poland, Romania, Slovenia and Slovakia

** Candidate EU MS = Croatia, Macedonia, and Turkey

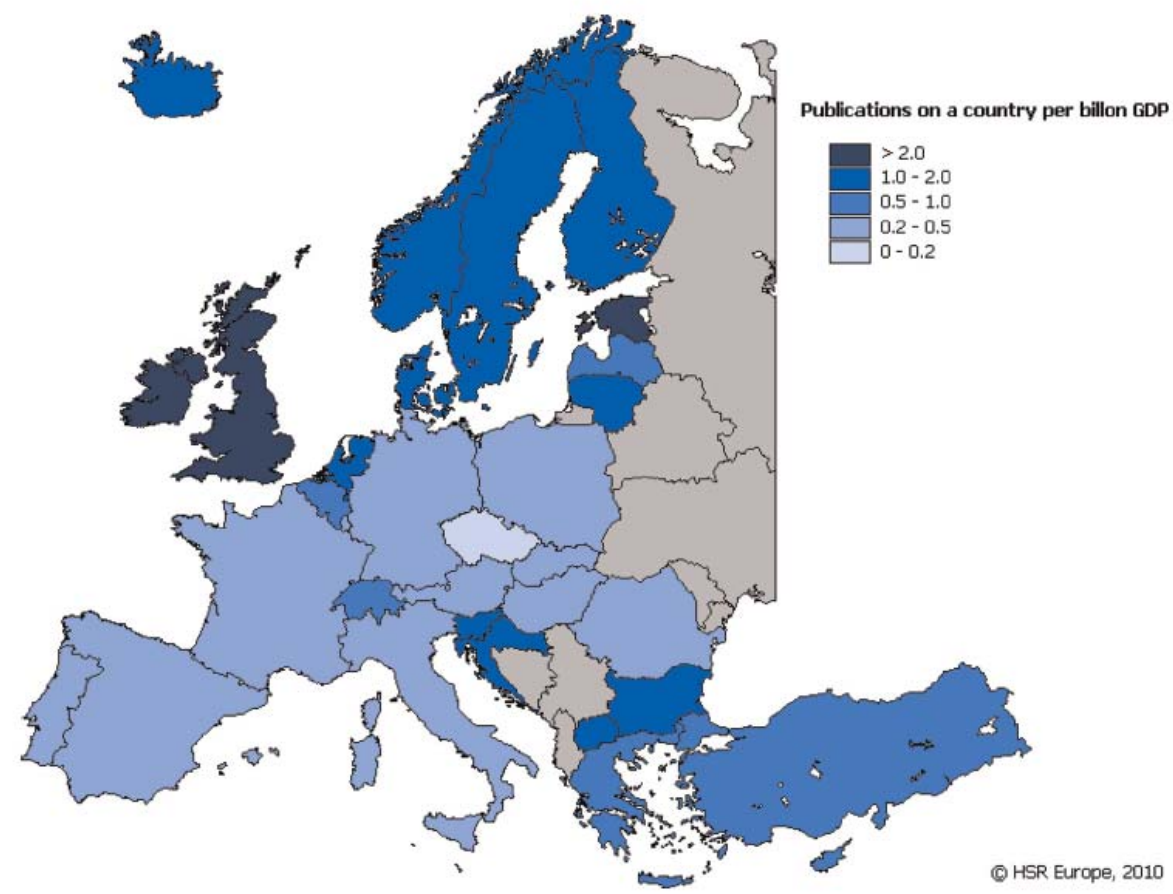

Figure 2 Average number of publications per billion GDP with country in keyword for all 33 European countries in the period 2000-09 
Hansen, J., Schäfer, W., Black, N., Groenewegen, P.P. European priorities for research on health care organizations and service delivery. Journal of Health Services Research \& Policy: 2011, 16(Suppl 2), 16-26
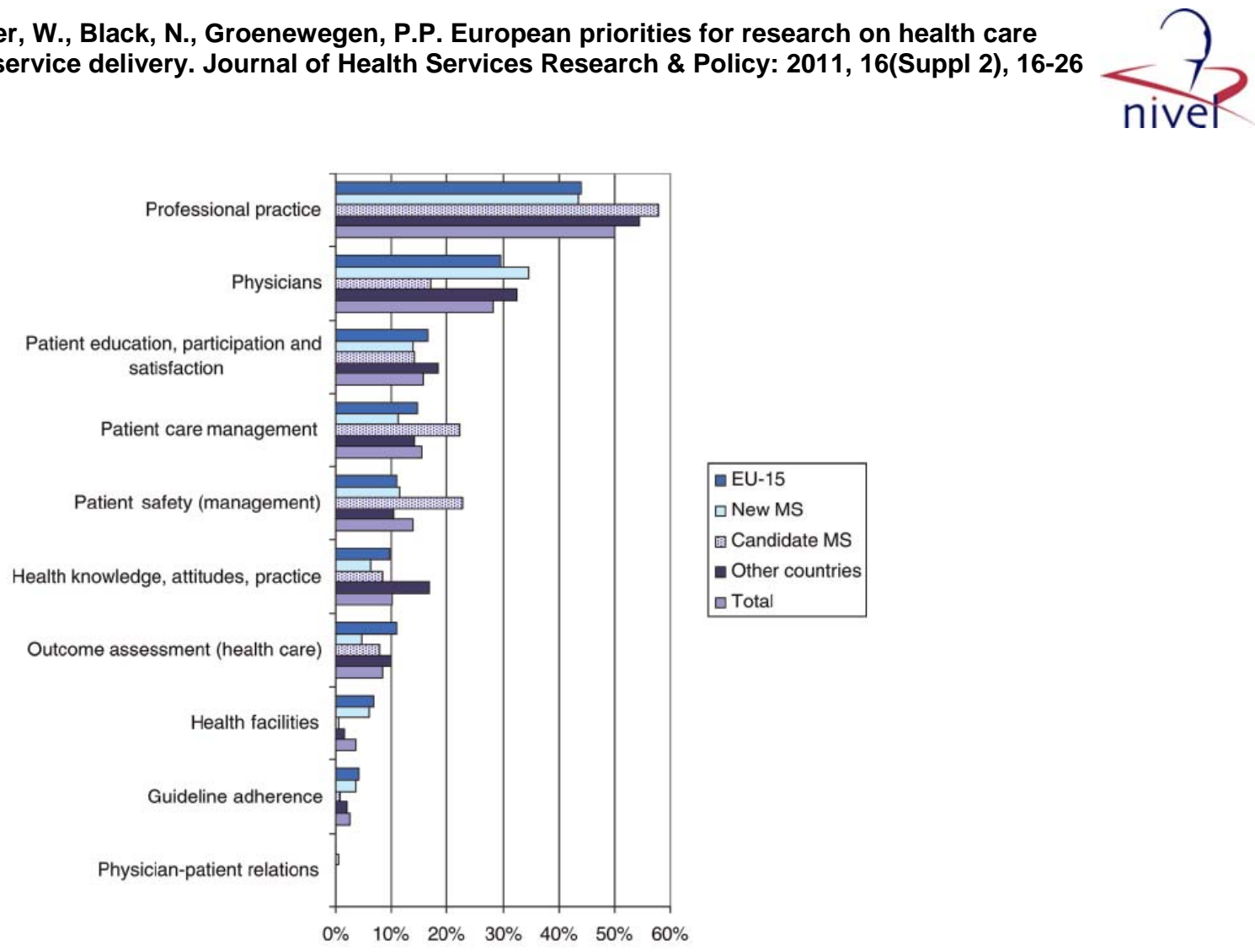

Figure 3 Ten most frequently occurring keywords in published research in the period 2000-09 by clusters of countries (as keywords). EU = European Union; $\mathrm{MS}=$ Member State

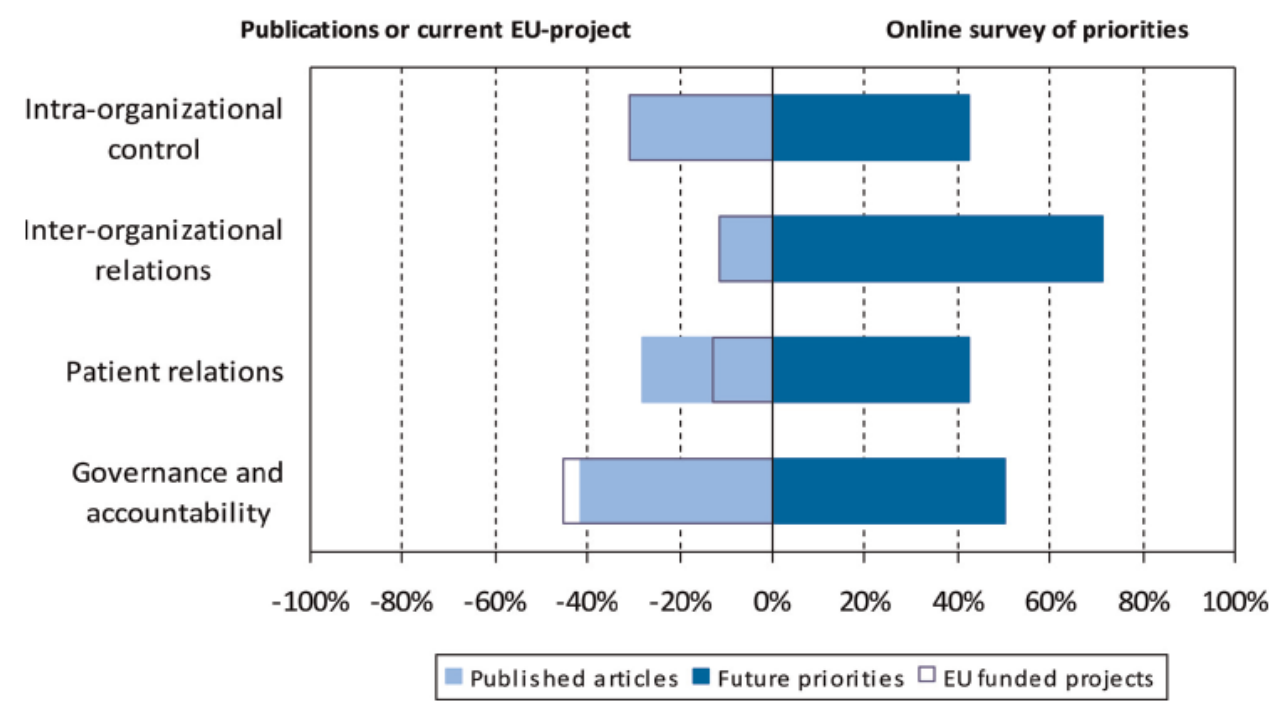

Figure 4 Comparison of past and current research areas with priorities for the next two to five years 
Hansen, J., Schäfer, W., Black, N., Groenewegen, P.P. European priorities for research on health care organizations and service delivery. Journal of Health Services Research \& Policy: 2011, 16(Suppl 2), 16-26

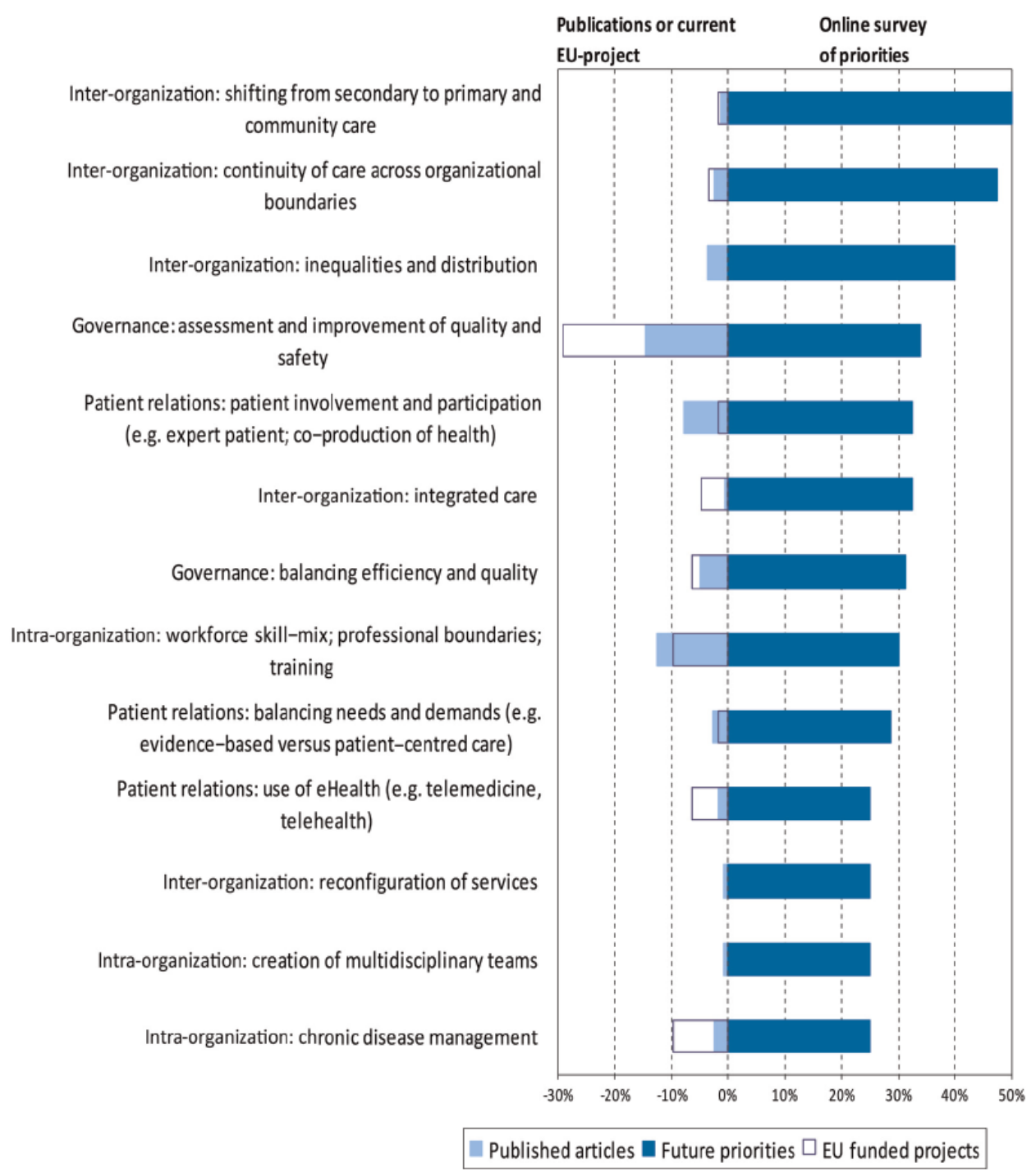

Figure 5 Comparison of past/current research topics with priorities for the next two to five years ( $25 \%$ or more), sorted in descending order 